\title{
Incorporation of Digital Transformation Aspects within the Supply Chain of Dairy Products; An Assessment of Implementational Feasibility of Blockchain, Automation, and ERP Systems within the Supply Chain Process
}

\author{
Mai Aldhaheri, Ousha Alshamsi
}

\begin{abstract}
This paper reviews the feasibility of the implementation of blockchain, autonomous systems, and ERP systems within a dairy supply chain to assess whether or not it is possible and how it can enhance the supply chain process. Utilizing secondary research, it is found that blockchain can be implemented with a theoretical model that is put forth in the paper. Autonomous systems on the other hand are proved to be far too difficult to implement due to the numerous conditional variables that would need to be considered for a universal automated system. Lastly, ERP has been already implemented within supply chains so the paper provides methods on how it can be enhanced by using remote devices and payment gateways to further streamline operations and enhance efficiency.
\end{abstract}

Index Terms-Digital Transformation, Supply Chain, Blockchain, Automation, ERP

\section{INTRODUCTION}

The main concern for a food supply chain has always been its efficiency, effectiveness, and reliability. Its disruption due to any number of reasons can be grounds for major concern. Rajan (2018) provides various examples of food and dairy contamination that aims to highlight the level of criticality that the industry and government need to understand and put forth measures to mitigate the issues [1]. The US Food and Drug Administration Report 2019 cites various instances where dangers of food contamination often go unnoticed. The food industry does its best to create and supply high-quality products that are free and safe from contaminants however they are limited by the technology at their disposal [39].

The problem of low quality and food contamination within the food industry is a global phenomenon and various organizations such as the EFSA (European Food Safety Authority) and USDA (United States Department of Agriculture) have tried to develop global safety standards for consumers products. However, there is still a major need to enhance the food chain by ensuring the sustainability and maintenance of food quality within the food chain.

There is a critical gap within current literature that prevents shedding light on potential solutions. One of the reasons as put forth by Mor et al. (2018) is that despite various

MAI ALDHAHERI, College of Engineering, Mathematics and Physical Sciences, University of Exeter, North Park Road, EX4 4QF Exeter, England, United Kingdom technological tools that can potentially be used, few can be implemented practically. Yet another reason is that the industry itself is complacent with its operations therefore they rarely partner with researchers to search for new solutions [2]. There is also a gap regarding the incorporation of digital transformation aspects within the dairy supply chain. Agrawal et al. (2019) acknowledges the gap and states that one of the major reasons for it is that business and industries do not want to take expensive risks in funding researches. They are content in using the old methods even though they are unreliable and inefficient [3].

Mor et al. (2018) state that the dairy industry has the $5^{\text {th }}$ most active supply chain in the world due to the high demand and supply as well as purchase rate [2]. Due to its increased activeness, a statistic of $13 \%$ is provided where the supply chain fails in the successful delivery of products to the end-user. Therefore, there is a need to understand how it can be improved and enhanced.

Therefore, to overcome this issue, data needs to be collected and analyzed to innovate the dairy supply process. The overall goal of the process is to improve the dairy supply chain and eliminate the safety issues of food and dairy products.

Various technologies have been proposed by researchers to mitigate the problems plaguing the dairy supply chain. Jachimczyk et al. (2021) put forth the utilization of IoT to enhance the computing and transactional speed of dairy products by different vendors. At the same time, various researchers have put forth the concept of utilizing blockchain for the transaction process [4]. Shingh et al. (2020) note that being a recently discovered technology that has revolutionized decentralized transactions, blockchain's potential within the supply chain is endless. The blockchain can incorporate the different vendors and supplies and generate smart contracts that are updated and sent to the users within the chain in real-time. This can significantly reduce processing and waiting time [5].

Automation is another key process that can be used to automate the system software that is used for the development of dairy products and their delivery. The records can be created and added to the database through UIPath and Power Automate, two of the leading automation tools within the software field. Lastly, Jadawala \& Patel (2018) states that Enterprise resource planning systems are also an adequate way to record and store data while transferring them to 
relevant parties so they can initiate the production and delivery process within the supply chain [6].

Out of all the different technologies proposed, this paper aims to analyze the implementational feasibility of blockchain, automation, and ERP systems within the dairy industry. Furthermore, it also aims to build upon existent knowledge by analyzing the various aspects of these technologies and how they can be integrated seamlessly, within the dairy industry's supply chain.

\section{A. Significance of Research}

Since there is a wide literature gap in the area, the originality of the research lends itself to its overall credibility. The area of focus is not without its significance since there is a rampant need for the dairy industry to upgrade its supply chain processes through innovating and implementing change strategies. The strategies can assist in identifying flaws and areas of improvement which can then be rectified. The research's aim to focus on the implementation of technologies within the supply chain of the dairy industry, followed by recommendations on how they can be improved through automating processes and implementing blockchain helps in building the current state of knowledge within the field. Such research has not been attempted before where the researcher is analyzing the feasibility of aspects of digital transformation that can be incorporated in the dairy supply chain process and recommend them based on the overall findings regarding their usefulness and feasibility.

This research adds to the current knowledge pool, since even though there are researches based around blockchains, automation as well as entity resource planning systems, however, seldom have been used within the context of a supply chain. The supply chain process that starts from the raw materials vendor to the end consumer is a step-by-step process that can benefit greatly from something like a blockchain that generates smart contracts at every step and helps keeps the people involved in the chain, updated about the process. This lack of research material thereby makes the research to be conducted, very innovative and ground-breaking as it will open up new possibilities for dairy businesses to start thinking outside the box. By applying this research in their business processes, the organizations will no doubt benefit from the new possibilities and functionalities.

\section{B. Research Question}

How can implementation aspects of blockchain, automation, and ERP systems be used to enhance the process of the supply chain within the dairy industry?

\section{Research Objectives}

- To assess the implementation of blockchain in Supply Chain Management.

- To analyze the feasibility of implementation of automation within the Supply Chain.

- To evaluate the functionality of Enterprise Resource Planning Systems in the Supply Chain.

\section{BACKGROUND}

\section{A. Blockchain}

Blockchain was first introduced as a concept in 2008 by Satoshi Nakamoto. The concept went hand in hand with the creation of a digital currency. However, blockchain as a whole is not limited to generating digital currencies but it can virtually be used for any activity that needs multiple complicated transactions and data storage. Blockchain is simply defined as a distributed and decentralized ledger system that holds all records of transactions that occur between members in a P2P network. The major principles of blockchain that include transparency, P2P transmission, security, and irreversibility of records make it ideal for supply chains where a product has to move through multiple parties to reach its end destination [8].

\section{B. Automated Processes}

Automation is the development and utilization of technologies to deliver services and goods with little to no human intervention. The implementation of automation aims to increase the reliability and efficiency of tasks that are otherwise performed by humans. These tasks are conducted both on the physical and digital sides. Specific tools allow users to create a sequence of routine tasks and hook it to a time scheduler. This allows the computer system to execute the sequence of tasks at that particular time [9].

\section{Enterprise Resource Planning Systems}

Jadawala \& Patel (2018) states that an ERP is a wide all-purpose system that efficiently combines and integrates all the required information and functionality of the operating process including human resources, material management, accounting, production, quality management, and sales [6]. The components and functionality differ from industry to industry and specific industries such as the dairy industry have specific operations that are exclusive for it. This includes measuring and estimating gallons of milk as output, the volume of raw materials that must be processed, and other specific aspects. This integrated information system aims to enhance the feasibility of manufacturing and the overall work performed in the industry.

A business needs to understand and make full use of the system as many simply use a portion of its functionalities while not engaging in others. It has been stated by Füzesi et al. (2018) that effectively using an ERP increases the output of the company and improves the firm's performance. With it being so popular in manufacturing, there is a case to be made to apply this system is within the dairy industry completely to bring about digital transformation [10].

\section{LITERATURE REVIEW}

\section{A. Blockchain in Dairy Supply Chain}

The need for traceability within the dairy supply chain has been suggested by multiple researchers [11]. However, a large number of people in the industry including farmers based in China prefer paper-based documents for traceability. They are far less likely to use a complex computer-based system such as blockchain. Though recent trends show that blockchain traceability has been applied to the food industry such as the Chinese Seafood industry [12]. Leading 
supermarket chains in UK and USA such as TESCO, Walmart and METRO have begun to use blockchain-based traceability systems to enhance their speed, accuracy, and convenience of transactions.

The concept of a tracking system based on blockchain was first put forth in 2015. Galvez et al. (2018) state that blockchain can be a potential tool that can help in the management and tracking of information across a supply chain to speed up the process of transport [13]. Provence, a UK-based company later announced their plan to create a blockchain tracking system for their fishery industry in the same year. The idea grew and practical applications of blockchain-based traceability systems were implemented in the supply chain of mangoes in the US, and pork in China by Walmart [14]. This was when the capabilities of the system were bought to light which allows the users to view far more information than just product tracking details. Information such as shipping details, storage temperatures could also be transmitted to the vendors and suppliers within the blockchain.

Multiple technologies have been integrated with blockchain to enhance the efficiency of the supply chain of dairy and nondairy products. While blockchain provides a platform to record information securely, the methods to gather this data allow for the utilization of the Internet of Things (IoT) to be used as well. The incorporation of these technologies that are often considered to be part of 'Industry 4.0' can enhance the dairy supply system greatly by providing accurate data and faster processing of products so that they may reach the consumer at a higher rate.

By increasing the visibility and traceability of dairy products, blockchain aims to reduce risk and uncertainty [15]. The assessment of blockchain functionalities provides sufficient evidence that there is a major potential for the technology's integration within dairy supply chains. The case study highlighted by Ying et al. (2018) showcases the major characteristics of blockchain and how it can improve a businesses' supply chain internal process such as vendors getting advance notifications, suppliers getting transaction contracts for evidence of deliveries as well as data protection [16]. However, Wang et al. (2019) believe that despite the advantages of blockchain utilization, the technology's immaturity, and unknown costs can cause major problems for the supply chain participants [17]. The adoption rates of blockchain within the dairy supply chain are provided by Queiroz \& Wamba (2019) who notes that developed countries are faster in adopting it as compared to developing countries [18].

Yet despite the problems, the advantages that this suite provides to the dairy supply chain cannot be ignored. The preservation of quality and safety of the raw materials and dairy products is a major factor in considering the adoption of blockchain. Blockchain can lower response times between different participants involved in the supply chain as well as improve the flow of goods and payments [19]. The improvement this technology can being into dairy operations includes increased profitability and food data security where blockchain can be used as a data management architecture. A significant decrease in food-borne illnesses is a benefit put forth by Shine et al. (2018) when adopting blockchain within the supply chain because the food is transported much faster [20]. The overall consensus of contemporary researches suggests that blockchain, therefore, has a great potential in enhancing operations, delivery, user experience, and efficiency of the dairy supply chain.

\section{B. Automation in Dairy Supply Chain}

Laxmi \& Mishra (2018) notes that the benefits of automation in the supply chain reduce the possibility of health hazards and contamination in foods for animals and humans. Furthermore, while the initial cost of implanting automation is high, it makes up for reducing costs of labor in the long term which is eventually passed on to the consumer in the form of lower-priced goods [21]. At the factory level, within the dairy supply chain, automation aims to produce consistent quality food products as well as reduce production costs. Furthermore, the speed and flexibility it provides to meet the demands of the market is something no other technology can provide.

The changing policies and legal demands for the supplication of dairy products can easily be accommodated into the automated process through tweaking the procedure. By increasing the production of the goods, automation also prevents any shortage of dairy products within the market. The safety and security of the operations cannot be denied alongside creating an effective avenue for reporting the production statistics [4].

Caria et al. (2019) state that the overall mission of implementing automation in a dairy farm's supply chain is to ensure the production of items cost-effectively with the qualities necessary to serve market demand. A holistic and systems approach is required for automating the production of dairy products as they are highly sensitive materials. The rate of efficiency increases by over $20 \%$ as automation also reduces the chances of human errors drastically, therefore not only resulting in better efficiency but also prevents waste of raw materials [22].

The implementation of automation however is a tedious process as fairy supply chains differ from manufacturer to manufacturer. One robust automation implementation cannot be simply installed at every factory. Each automated process needs to be customized specifically to the factory's unique structure. This can take a lot of time and exceeding costs may very well prevent the factory from installing the process. Therefore, the variables of time, cost, resources, and expected results become crucial in the process of implementing automation.

The research conducted by Prasad (2017) also suggests that using bots within the supply chain proves is only feasible if the conditions of the manufacturing process are constant all the time [23]. However, in practical work, one often observes that is not the case. Fluctuations in the manufacturing process need to be made depending on the circumstances. These fluctuations can be anything, the amount of raw material, the heating temperatures among others. In such cases, automation would not be able to deliver the results as the process of automation simply involves repeating the steps that are fed into the system. The system cannot distinguish when alterations need to be made This obstacle has prevented the implementation of automation in many dairy supply chains globally.

\section{ERP utilization in Dairy Supply Chain}

Out of the three technologies being discussed in this paper, ERPs are the most commonly used aspect of digital 
transformation within the dairy supply chain today. However, as Jadawala \& Patel, (2018) notes that even the number of ERP implementations falls short as only $23 \%$ of the dairy industry makes proper use of ERP systems to enhance supply chains. One crucial reason is that ERP systems require a technical mind and knowledge of the system [6]. Most workers, especially in China, Bangladesh, and India within the Dairy industry are not technically proficient. This makes them unable to make full use of the system, and the system is often neglected or not used to its full potential. There is a recurring problem where the companies have bought the ERP system from a third-party company but over time, the employees with experience on the system leave without passing the knowledge to newcomers. As such over time, the rate of usage decreases leading to slower processes and manual work.

When utilized correctly, ERPs have the potential of making the supply chain work faster, reliable, and efficient. Oghazi et al. (2018) state that ERPs within the dairy supply chain are all customized and uniquely tailored to the specifics of the dairy industry. This includes information from farms, the rates, the poultry, the estimate of raw materials that can be procured as well as remote orders for warehouse and inventory checks [24]. Since an ERP is massive for one individual to handle all by himself, many employees can take over certain sections. Suppliers update the supply section of the ERP while transport personnel update the vehicles and delivery system. These are then made accessible to others who can gain visibility of the overall operations.

ERP implementation has been increased in recent years with more companies within the Dairy industry embracing the systems to streamline their management and logistic process. Asian countries have begun to apply for specific ERP subscriptions where the ERP system is lent on a superscription basis. This allows the companies to get a Table I Systematic Literature Review Process (Adapted from Tranfield et al. (2003)) [40]

\begin{tabular}{|l|c|}
\hline Steps & Processes \\
\hline Step 1: Identification of Data & - Keyword Identification \\
& - Data Source Identification \\
& - Research Paper selection \\
\hline Step 2: Data extraction & - Qualitative assessment \\
& - Data extraction and synthesis \\
\hline Step 3: Data analysis & - Analysis of literature \\
& - Isolating and reporting on findings \\
& - Assessment potential for future research
\end{tabular}

\section{A. Identification of Data}

The papers were isolated using keyword frequency which incorporates the utilization of relevant keywords to narrow the number of literature papers to review. The keywords were deliberately kept as generic as possible to increase the output of research papers from the search engine. 20 search terms were used that came about as a result of multiple keyword combinations. The initial keyword set highlighted the familiarity with the system beforehand before shifting their entire business on it. The scope of shifting a dairy business from a non-ERP channel to one that primarily revolves around ERP is not an easy task [25]. This is also a prime reason why companies are unable to adopt ERP into their operations.

While ERPs mostly benefit the companies that use them, few drawbacks come with their adoption. One of which is that since it is a software system, therefore it is possible to infiltrate or hack it. Yet another problem is data corruption. In both cases, data can be lost and information material damaged which can impact operations and the supply chain processes. To overcome these many ERP revisions come bundled with security protocols and encryption that prevents data from being leaked. User access levels can also prevent unauthorized users from accessing data that is not needed for them. At the same time, these security protocols aim to keep malicious hackers from breaking into the system. While these attempts have been mostly successful, Gao (2020) provides a few notable examples where ERP systems were compromised and data was leaked [26].

\section{Methodology}

The research was undertaken by unitizing a secondary research method using a systematic literature review technique. This method allowed the researcher to assess and evaluate researches that were conducted in the same domain and use their arguments and statements to justify the need to implement digital transformation in the supply chain. These prior researches were instrumental in highlighting how digitization can be introduced within this sector. The overview of the process is provided in the key steps below.
- Assessment potential for future research

technology (Blockchain, Automation, ERP). The second keyword set highlighted the supply chain aspect (Dairy Supply Chain, Supply Chain, Logistics, etc.), while the third keyword set was concerned with the operations of the supply chain (Operation, Distribution, Manufacturing, etc. The table below highlights some of the keywords for the relevant technologies. Due to limitations, the entire keyword set cannot be provided. 
Table II Keywords

\begin{tabular}{|l|l|}
\hline Technology Field & Keyword Formation \\
\hline Blockchain in Dairy Supply Chain & $\begin{array}{l}\text { Blockchain Logistics Operation, Blockchain Supply Chain } \\
\text { Distribution, Blockchain Dairy Manufacturing }\end{array}$ \\
\hline Automation in Dairy Supply Chain & $\begin{array}{l}\text { Autonomous System Supply Chain, Automation Dairy } \\
\text { Supply Chain, Robot Supply chain logistics }\end{array}$ \\
\hline ERP in Dairy Supply Chain & $\begin{array}{l}\text { ERP Dairy Supply Chain Operations, ERP Installation Supply } \\
\text { Chain, ERP Supply and Logistics. }\end{array}$ \\
\hline
\end{tabular}

\section{A. Data Collection}

Three different databases were used to gain access to the research material. This includes EBSCO's search engine, the JSTOR library Database as well as Google Scholar. All these sources were utilized to find current research appears that relates to the incorporation of digital transformation within the supply chain.

\begin{tabular}{|l|l|l|l|l|}
\hline Technologies & \multicolumn{4}{|l|}{ Number of Papers } \\
\hline & EBSCO & $\begin{array}{l}\text { JSTOR } \\
\text { Database }\end{array}$ & $\begin{array}{l}\text { Google } \\
\text { Scholar }\end{array}$ & $\begin{array}{l}\text { Final } \\
\text { Research } \\
\text { Paper } \\
\text { count }\end{array}$ \\
\hline Blockchain & 7 & 6 & 5 & 18 \\
\hline Automation & 3 & 2 & 3 & 8 \\
\hline ERP & 4 & 7 & 4 & 15 \\
\hline \multicolumn{5}{|l}{ Total } \\
\hline
\end{tabular}

Table III Research Paper Review Count

Table 2 showcases the number of research papers extracted from each database per the relative technology. It also highlights the number of papers that were then excluded after the application of exclusion criteria, with the final number of research papers being provided. The total number of papers about Blockchain implementation was 18,8 belonged to Automation feasibility while 15 belonged to ERP establishment. This bought the final literature analysis count to 41 papers.

\section{B. Inclusion and Exclusion Criteria}

Various criteria were used to select the papers. These criteria were created by the researcher helped to further narrow the scope of the research, therefore, resulting in the extraction of highly relevant papers that were critical to the current research topic's theme. The inclusion criteria were as follows. The papers must not be more than 15 years old. The authors must have written multiple papers within the same industry thereby establishing their credibility within the industry. The researches also had to be in full English language and the articles should be open access where the full text was available.

The exclusion criteria were as follows. Any articles in a language other than English were discarded. Furthermore, any articles in which the content was too narrow or too general were also excluded. Conceptual papers, conference abstracts were not considered for use wither. Lastly, blogs and non-research articles were not considered.

\section{Data Analysis}

Data Analysis was conducted through a qualitative data assessment method which is known as systematic analysis. The systematic analysis breaks down the aspects of digitization into different themes and technology, which allows the researcher to expand upon how each different technology can be integrated within the supply chain department and what purpose and benefits it serves. This form of a unique analysis can lead to an assessment of the feasibility of these technologies and how viable they are from the perspective of project management. Ultimately, this helped in expanding upon the research objectives and expanding upon the answer to the research question.

\section{Ethical Considerations}

Pietilä et al. (2020) highlight the importance of researching in an ethical way that is pertinent to the success of the research itself [27]. The data used in this study was double-checked for its reliability and validity. Furthermore, by using authentic sources and discarding data from blogs and tabloids, the research accuracy was enhanced. Lastly, all data that was acquired from other researches and used, is properly credited to the original author.

\section{FINDINGS AND DISCUSSION}

\section{A. Implementational Feasibility of Blockchain within the Dairy Supply Chain}

It can be observed from the literature that blockchain has been implemented in various supply chains around the world however its execution is very haphazard. Casino et al. (2020) notes the practical problems that occur in the implementation and how the supply chain process is not standardized which can cause problems when implementing a blockchain system with specific stakeholders and transactions [28]. Similarly, Kasten (2019) believes that many organizations implement blockchain however, scarcely use it as they do not understand which parties to involve within the supply chain process [29]. Therefore, we have created a theoretical model of the entire daily supply chain which can then be fully converted to be made compatible with blockchain utilization. The model has its specific markers at which points the transaction notification should be sent to each user and at the points, the smart contract is generated. This unified model, if implemented in the dairy supply chain with organizations has the potential to enhance the overall process by ensuring that visibility of each process is made available to the stakeholders. At the same time, the users can track the whole 
process and be aware of the journey that the raw material is taking from its inception to its destination.

Generation of Smart Contracts for visibility and tracking

Absence of Smart Contract Generation

Route 1

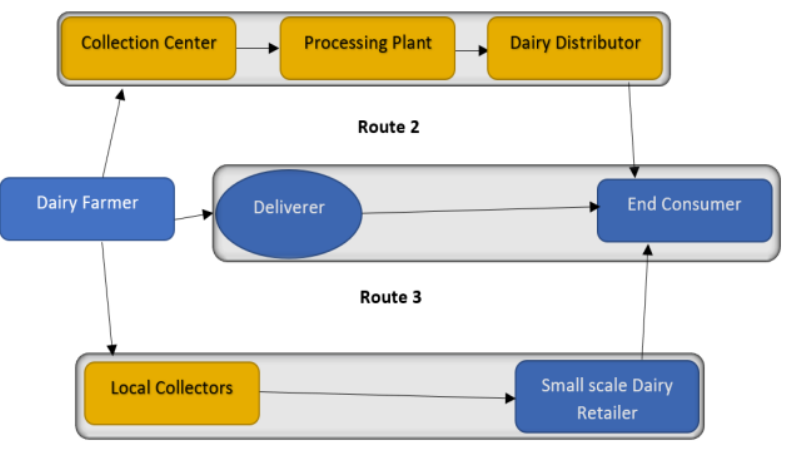

Fig 1 Blockchain Implementation Theoretical Model

Figure 1 showcases the theoretical model. There are three routes of the dairy supply chain. The Blockchain implementation is done at Route 1 and Route 3. The Yellow points are where notifications are created and smart contracts are generated, while the blue points are areas that are not included in the blockchain. This is as Shingh et al. (2020) state a semi-implementation of blockchain, where the chain is established in the system but the update point is not present at all points. Rather there are select few update points that are placed strategically throughout the blockchain [5].

From Route 1, once the dairy materials are collected from the farm, the collection center can update the blockchain process which would result in the generation of a smart contract and an alert will be sent to all users within the blockchain that the materials have arrived at the center. Once they are sent to the processing plant, the plant operators can again accept the transaction which would generate another smart contract at that point and will notify other users that the dairy materials have arrived at the plant. The same process will be repeated once the processed material arrives at the distributor. At this point, there will be a final generation of Smart Contract since the next step is to deliver the products directly to the consumer.

On Route 2, there is no blockchain implementation and thus the products will directly go to the deliverer who is then responsible for transferring them to the end consumer. On route 3, the Local Collectors' marker is incorporated within the blockchain who will then accept the transaction which will create a smart contract and then transfer the finished products to the dairy retailers, and from there to the consumers.

There are several reasons as to why a Semi-Implementation approach is chosen here. Route 1 comprises large-scale centers that are running various technological systems. Therefore, the environment, as well as the workers, can easily get accustomed to blockchain which is essentially just a new piece of technology designed for better tracking and visibility of materials. This includes the collection center, the processing plant as well as the distributors. Route 2 however is solely used for ready-made products where the products are sent to the deliverer who delivers them to the consumer. There is a high chance that the farmer nor the deliver has exposure to technological systems and would actively reject using technology for tracking and enhancing delivery speed. This theory is corroborated by Tan \& Ngan (2020) who notes that parties present in the supply systems around the world including India, China, and other parts of Africa and Asia are not proficient in using computer systems and technological artifacts [11]. They prefer doing their work manually. Therefore, if Route 2 was included within the blockchain, it would be actively rejected by the parties involved. Lastly, Route 3 implements the chain at local collectors who already use ERPs and other systems for storing data They would not be opposed to adopting blockchain as a way of enhancing the process. However small-scale delivery retailers in Route 3 are just small shops that sell dairy products and as such, it would not be advisable to include that point within the blockchain.

The proposed model also has the potential to mitigate the pitfalls of implementing blockchain [28] within the dairy supply chain. This is achieved through every user having access to mobile devices that can be used to receive smart contracts so that they can stay updated on the entire process. The system also has a flaw since the dairy supply chain also incorporates health inspectors who spend time ensuring that records are generated and kept correctly. With such a dynamic system in place, they will have problems in inspecting the materials and ensuring that all inventory is organized and categorized.

\section{B. Feasibility of Automation and Autonomous Systems in} Dairy Supply Chain

From the analysis of the literature, it could be seen that drones can assist farmers in procuring raw materials and can overhaul the operational levels of farms which is the starting point of the dairy supply chain. Automation can also be potentially implemented at the later stages within the supply chain where the materials are handled by the processing plants and distributors.

However, the majority of the literature highlights various restraints and constraints that make it difficult for automation to be properly implemented within the supply chain [30]. A supply chain can include a large number of participants, this includes importers, exporters, farmers, suppliers as well as retailers and consumers. This large, overbearing, and complex structure reduces the feasibility of automated implementation which typically works with routine processes and a small standard number of parties [31]. Since the process is so dynamic and ever-changing, it is not worth the finance and resources to implement such an expensive feature that would not achieve a full $100 \%$ functionality [32]. The adoption of autonomous systems and robotics, as Doukidis et al. (2007) puts it, the system requires a proper infrastructure and information to operate efficiently and be maintained by workers [33]. Food companies and dairy industries do not have the funds, resources, or access to employ highlight technical people especially when their process is in disarray. The food supply chain is a haphazard process and while it benefits from digital transformation, there is a limit to its implementation. While blockchain technology has shown the feasibility of implementation, autonomous systems show resistance. 
Khan et al. (2018) also note that the issues presented in food and dairy products such as variations in volume, size, the shape can cause discrepancies in automated measuring methods. The premise of replacing humans with bots is indeed attractive but they cannot account for the wide variety of discrepancies that measurement of dairy products brings to the table [34].

Furthermore, as Jagtap \& Rahimifard (2019) state, dairy manufacturers are largely hesitant to accept autonomous systems because the process generates a large amount of data which increases the concern regarding privacy and data security. The process that revolves around product movement and transport, and stakeholders being kept in the loop cannot be put at risk where security might get compromised and data leaked to competitors [35].

Companies getting hacked and their information stolen and sold on the internet is not new. The same can happen to dairy producers and food manufacturers if they bought strict automation within their supply chain. This is because an automation system requires full access to the dairy processing and transport systems. Essentially all firewalls and security measures need to accept a foreign entry of the automation system. Any $3^{\text {rd }}$ party can then fool the system into believing it is the automation process and get access to the secure data within.

This is one of the main reasons that dairy supply chains do not extend their operations globally and prefer working in small local areas providing their products to those that are close to them in terms of distance. Many of these organizations are small and medium-sized (SMEs) so they do not have the funds to implement autonomous systems either. Even if they did, they would not accept such a system [33].

Due to the various technical issues and difficulties that are found during the research, it is concluded that automation cannot be implemented in dairy supply chains as of yet. The way the process is built and runs, actively reject the incorporation of a third-party automated process, therefore a theoretical model cannot be created for this.

To make them compatible, the supply chain will need to shift to a largely routine process with little to no deviations in its process chain. However, since the process chain involves dozens of participants, all of which are human and prone to errors, this is a very tall order, one that cannot be achieved shortly.

\section{ERP Implementation feasibility within Dairy Supply Chain}

Unlike autonomous systems, ERP systems have already been integrated within the supply chain. Many dairy companies locally and internationally use ERPs to store, record, and transfer data that is related to dairy materials moving within the supply chain. However even though, the implementation precedence has already been set, there is no reason why the process cannot be enhanced and upgraded to deliver more efficiency. As Adaileh \& Abu-Alganam (2010) notes, ERP can not only track all inputs but can also manage and keep records of inventory such as cattle feed and vaccine, therefore it can allow for supply chain factories to make their process more efficient [36]. However, their research also suggests that while ERPs are implemented, they are not used to their full potential. Many functionalities are simply not taken advantage of or are ignored with only some parts being used [37]. This negates the whole point of the ERP system. This is why it is critical for processing plants and dairy factories to take a more in-depth look into their system and see what it has to offer [7]. They can make use of these functionalities and greatly streaming the supply chain process and make it easier and more profitable. Therefore, this section of the paper provides suggestions on how the implementation of ERPs can be enhanced [7]

Since many ERPs are compatible with mobile devices and the Internet of Things (IoT), specific apps can be created for these devices which can be used by individual parties to update the data entries which are then remotely sent to the ERP. The ERP then stores this data in a central database and allows other parties to access it when they need it.

Following are the ways how mobile devices can be used with ERPs to streamline the supply chain.

Table 1 Benefits of mobile application integration with ERP in Dairy Supply Chain

\begin{tabular}{|l|l|}
\hline Local Farmers & $\begin{array}{l}\text { Processing Plant Employees } \\
\text { and transporters }\end{array}$ \\
\hline $\begin{array}{l}\text { Farmers can access their } \\
\text { purchase and sales history }\end{array}$ & $\begin{array}{l}\text { The processing factory } \\
\text { employees can enter the } \\
\text { received amount in their } \\
\text { database system }\end{array}$ \\
\hline $\begin{array}{l}\text { Farmers can review their } \\
\text { monthly payments }\end{array}$ & $\begin{array}{l}\text { The employees can access } \\
\text { and review reports of } \\
\text { monthly and annual dairy } \\
\text { supply and sales }\end{array}$ \\
\hline $\begin{array}{l}\text { Farmers can log requests for } \\
\text { pickup and drop-offs }\end{array}$ & $\begin{array}{l}\text { The mobile application can } \\
\text { also be used by transporters } \\
\text { to log in transport time, date, } \\
\text { and destination drop-offs. }\end{array}$ \\
\hline
\end{tabular}

Similarly, IoT devices can be integrated with the ERP system to provide feasibility to the overall functionality.

- IoT devices can be used to obtain real-time data of output from each farm animal.

- IoT can be utilized to track dairy products moving through the supply chain in real-time which can improve the supply chain

- IoT implementation enhances the chances of reporting accurate information

- IoT can also be used to keep track of each respective animal's health on the farm. 


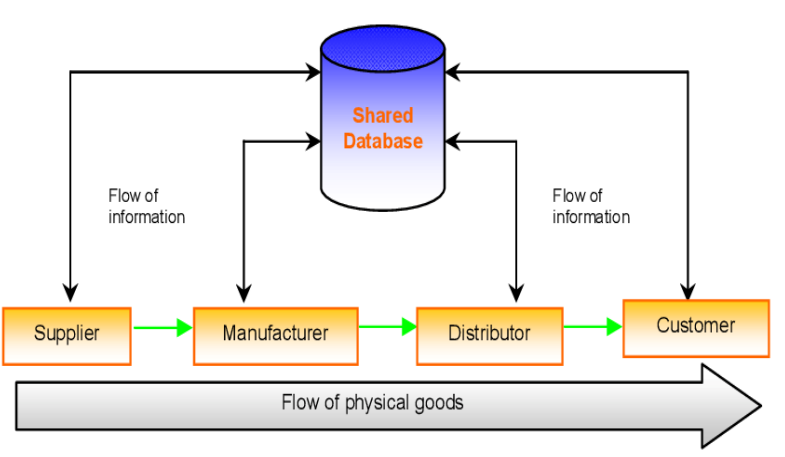

Fig 2 ERP with multiple compatibility range; A Diagram by Ghani et al. (2009) [38]

Figure 2 shows how ERP compatibility will work with different devices. Each of the different entities, supplier, manufacturer, and distributor are connected to the ERP's shared database. The mobile device can act as an auxiliary that would remote send data entered into the application directly to the storage system in the ERP.

So, when suppliers ship their products out, they can enter data through their mobile device that shows that they have shipped. This will alert the other parties such as the manufacturers that the materials have been shipped and they should anticipate it. When the materials arrive, they can be sent to processing and the manufactures can update the data on their end to store the updated information in the database and let the other parties know that the data has been sent to processing. This can then be repeated at the distributor level until the materials finally arrive at the shop and customers purchase them. This ERP storage and updates in real-time in many ways look similar to the proposed blockchain technology implementation.

Through these methods, IoT can make the farmer and processing plants' jobs easier by providing then access to readily available data that is stored within the ERP.

At the same time, ERPs can also impellent payment gateways which can be used to remotely pay the third parties for their products and services. There are several advantages to implementing this gateway within the ERP.

- Payment gateways can reduce the risk of malpractices involved in making payments. This includes bribery, money laundering, and payment delays

- Gateways can also be linked to databases that can store a record of how much each payment was worth along with the time and source of payment.

- Payment gateways can also allow people with less proficiency in technology to receive payments such as farmers.

- Farmers can also secure payments for insurance cattle feed, maintenance of animals, etc.

With these three independent applications (mobile devices, IoT, payment gateways) working conjointly with the ERP system, the implantation of the ERP can receive a significant boost and will allow for the organization to lean onto it more heavily rather than look for third party solutions to problems that can be solved with the ERPs' integration modules. The unique aspect of ERPs is their ability to connect to applications and devices which is what many companies do not take advantage of [7]. However, if what is presented in this paper is followed by dairy supply chain organizations, they will see a significant increase in their profitability and feasibility.

\section{CONCLUSION}

With all three technologies that are under the spectrum of digital transformation, analyzed and evaluated, in terms of their implementation feasibility, various aspects were discovered. The implementation of blockchain is quite recent and has yet to be adopted at a wider rate. Therefore, a model is proposed on how blockchain transactions can be used within the dairy supply chain to increase its rate of adoption. For ERPs, it is evaluated that it is already being implemented, however, their full functionality is not being taken advantage of, leaving a very halfhearted and haphazard implementation. This cause problem for companies who conduct a portion of their supply chain work on the ERP and the rest of the tasks external to the ERP. Therefore, various integration modules were suggested to increase the usability factor of ERPs so that dairy supply chain management teams can use remote devices, payment gateways, and IoT devices to streamline their process.

Lastly, with autonomous systems, it can be concluded that there is no feasible e way to attempt its implementation due to a large number of factors, considerations as well as the different parties involved. There is however hope for its implementation in the future if autonomous systems are made more user-friendly and the dairy supply chains start to standardize their process.

\section{RECOMMENDATIONS}

The fact that this paper only utilized secondary research is a limitation that holds the research back. Therefore, it is recommended for future researchers who choose to research this particular area, to conduct primary research and experiments to quantify the feasibility aspect of digital transformation and its incorporation in dairy supply chains.

Secondly, it is also recommended for researchers to find alternate solutions to the implementation of autonomous systems. Since this research could not discover any feasible method to implement it, hopes can be placed on future researches to find compatible methods. Lastly, this research can be used as a foundation platform for those willing to research the aspect of digital transformation in supply chains, thereby it is recommended for those researchers to utilize this research in their work.

\section{REFERENCES}

[1] Rajan, N. (2018). 3 of The Worst Dairy Recalls of 2017 - Xtalks Retrieved 3 June 2021, from https://xtalks.com/3-of-the-worst-dairy-recalls-of-2017/

[2] Mor, R. S., Bhardwaj, A., \& Singh, S. (2018). Benchmarking the interactions among performance indicators in the dairy supply chain. Benchmarking: An International Journal.

[3] Agrawal, P., Narain, R., \& Ullah, I. (2019). Analysis of barriers in the implementation of digital transformation of supply chain using an interpretive structural modeling approach. Journal of Modelling in Management.

[4] Jachimczyk, B., Tkaczyk, R., Piotrowski, T., Johansson, S., \& Kulesza, W. (2021). IoT-based Dairy Supply Chain-An Ontological Approach. Elektronika ir Elektrotechnika, 27(1), 71-83.

[5] Shingh, S., Kamalvanshi, V., Ghimire, S., \& Basyal, S. (2020). Dairy supply chain system based on blockchain technology. Asian Journal of Economics, Business, and Accounting, 13-19. 
[6] Jadawala, R., \& Patel, S. (2018). Implications of disruptive ICT-based ERP in the dairy industry (in the aspects of milk co-operatives and cattle farms). Journal of Emerging Technologies and Innovative Research, 5(10), 331-336.

[7] Jadawala, R., \& Patel, S. (2019). Improving Milk cooperative governance through ERP System. Book chapter in Cooperatives for Sustainable Rural Development Publisher: Reliable, Ahmedabad.

[8] Nofer, M., Gomber, P., Hinz, O., \& Schiereck, D. (2017). Blockchain. Business \& Information Systems Engineering, 59(3), 183-187.

[9] Huhns, M. N., Stephens, L. M., \& Ivezic, N. (2002, July). Automating supply-chain management. In Proceedings of the first international joint conference on Autonomous agents and multiagent systems: part 3 (pp. 1017-1024).

[10] Füzesi, I., Felföldi, J., Csordás, A., \& Lengyel, P. (2018). Analysis of the application of ERP systems at Hungarian meat companies. Journal of Ecoagritourism, 14(1), 23-28.

[11] Tan, A., \& Ngan, P. T. (2020). A proposed framework model for dairy supply chain traceability. Sustainable Futures, 2, 100034.

[12] Cook, B., \& Zealand, W. N. (2018). Blockchain: Transforming the seafood supply chain. World Wide Fund for Nature.

[13] Galvez, J. F., Mejuto, J. C., \& Simal-Gandara, J. (2018). Future challenges on the use of blockchain for food traceability analysis. TrAC Trends in Analytical Chemistry, 107, 222-232.

[14] Kamath, R. (2018). Food traceability on blockchain: Walmart's pork and mango pilots with IBM. The Journal of the British Blockchain Association, 1(1), 3712.

[15] Min, H. (2019). Blockchain technology for enhancing supply chain resilience. Business Horizons, 62(1), 35-45.

[16] Ying, W., Jia, S., \& Du, W. (2018). Digital enablement of blockchain: Evidence from HNA group. International Journal of Information Management, 39, 1-4.

[17] Wang, Y., Singgih, M., Wang, J., \& Rit, M. (2019). Making sense of blockchain technology: How will it transform supply chains?. International Journal of Production Economics, 211, 221-236.

[18] Queiroz, M. M., \& Wamba, S. F. (2019). Blockchain adoption challenges in the supply chain: An empirical investigation of the main drivers in India and the USA. International Journal of Information Management, 46, 70-82.

[19] Akkerman, R., Farahani, P., \& Grunow, M. (2010). Quality, safety, and sustainability in food distribution: a review of quantitative operations management approaches and challenges. Or Spectrum, 32(4), 863-904.

[20] Shine, P., Murphy, M. D., Upton, J., \& Scully, T. (2018). Machine-learning algorithms for predicting on-farm direct water and electricity consumption on pasture-based dairy farms. Computers and electronics in agriculture, 150, 74-87.

[21] Laxmi, A. R., \& Mishra, A. (2018). Automation in supply chain management system using Internet of Things (IoT). International Journal of Engineering \& Technology, 7(2), 777-783.

[22] Caria, M., Todde, G., \& Pazzona, A. (2019). Evaluation of automated in-line precision dairy farming technology implementation in three dairy farms in Italy. Front Agric. Sci. Eng, 6, 181-187.

[23] Prasad, S. (2017). Application of Robotics in Dairy and Food Industries: A Review.

[24] Oghazi, P., Rad, F. F., Karlsson, S., \& Haftor, D. (2018). RFID and ERP systems in supply chain management. European Journal of Management and Business Economics.

[25] Khan, U., Asim, M., \& Manzoor, S. (2020). Improving supply chain management of a distribution firm using ERP System. European Journal of Business and Management Research, 5(2).

[26] Gao, L. (2020). Exploring the data processing practices of cloud ERP-A case study. Journal of Emerging Technologies in Accounting, 17(1), 63-70.

[27] Pietilä, A. M., Nurmi, S. M., Halkoaho, A., \& Kyngäs, H. (2020). Qualitative research: Ethical considerations. In The application of content analysis in nursing science research (pp. 49-69). Springer, Cham.

[28] Casino, F., Kanakaris, V., Dasaklis, T. K., Moschuris, S., Stachtiaris, S., Pagoni, M., \& Rachaniotis, N. P. (2020). Blockchain-based food supply chain traceability: a case study in the dairy sector. International Journal of Production Research, 1-13.

[29] Kasten, J. (2019). Blockchain Application: The Dairy Supply Chain. Journal of Supply Chain Management Systems, 8(1).

[30] FAO, G. (2011). Global food losses and food waste-Extent, causes, and prevention. SAVE FOOD: An Initiative on Food Loss and Waste Reduction.

[31] Vandeplas, A., Minten, B., \& Swinnen, J. (2013). Multinationals vs. cooperatives: The income and efficiency effects of supply chain governance in India. Journal of Agricultural Economics, 64(1), 217-244.
[32] Leonello, T., Andrea, A., Filippo, C., Rana, R. L., Gualtiero, F., \& Angela, T. (2019). From Precision Agriculture to Industry 4.0: unveiling technological connections in the agricultural sector.

[33] Doukidis, G. I., Matopoulos, A., Vlachopoulou, M., Manthou, V., \& Manos, B. (2007). A conceptual framework for supply chain collaboration: empirical evidence from the agri- food industry. Supply Chain Management: an international journal.

[34] Khan, Z. H., Khalid, A., \& Iqbal, J. (2018). Towards realizing the robotic potential in future intelligent food manufacturing systems. Innovative food science \& emerging technologies, 48, 11-24.

[35] Jagtap, S., Bhatt, C., Thik, J., \& Rahimifard, S. (2019). Monitoring potato waste in food manufacturing using image processing and the internet of things approach. Sustainability, 11(11), 3173.

[36] Adaileh, M., \& Abu-Alganam, K. (2010). The role of ERP in supply chain integration. International Journal of Computer Science and Network Security, 10(5), 274-279.

[37] Angolia, M. G., \& Pagliari, L. R. (2018). Experiential learning for logistics and supply chain management using an SAP ERP software simulation. Decision Sciences Journal of Innovative Education, 16(2), 104-125.

[38] Ghani, K., Zainuddin, Y., \& Ghani, F. (2009). Integration of supply chain management with internet and enterprise resource planning (ERP) systems: A case study. vol, 1, 97-104.

[39] [39] Outbreak Investigation of E. coli: Romaine (November 2019). (2020). Retrieved 3 June 2021, from https://www.fda.gov/food/outbreaks-foodborne-illness/outbreak-invest igation-e-coli-romaine-salinas-california-november-2019

[40] Tranfield, D., Denyer, D., \& Smart, P. (2003). Towards a methodology for developing evidence- informed management knowledge using systematic review. British journal of management, 14(3), 207-222. 